\title{
Metabolism of Pantethine in Cystinosis
}

Carl T. Wittwer, William A. Gahl, Jean DeB. Butler, Martin Zatz, and Jess G. Thoene

Department of Pediatrics, University of Michigan Medical School, Ann Arbor, Michigan 48109; Interinstitute Genetics Program, Clinical Center, National Institutes of Health; Section on Biochemical Genetics, Human Genetics Branch, National Institute of Child Health and Human Development; and Laboratory of Cell Biology, National Institute of Mental Health, Bethesda, Maryland 20205

\begin{abstract}
D-Pantethine is a conjugate of the vitamin pantothenic acid and the low-molecular-weight aminothiol cysteamine. Pantethine is an experimental hypolipemic agent and has been suggested as a source of cysteamine in the treatment of nephropathic cystinosis. We treated four cystinotic children with $70-1,000 \mathrm{mg} / \mathrm{kg}$ per $\mathrm{d}$ oral D-pantethine and studied its metabolism. Pantethine was rapidly hydrolyzed to pantothenic acid and cysteamine; we could not detect pantethine in plasma after oral administration. The responsible enzyme, "pantetheinase," was highly active in homogenates of small intestinal mucosa and plasma. The Michaelis constant of the rat intestinal enzyme was $4.6 \mu \mathrm{M}$ and its pH profile showed a broad plateau between 4 and 9 . Pantothenate pharmacokinetics after orally administered pantethine followed an open two-compartment model with slow vitamin elimination $\left(t_{1 / 2}=28 \mathrm{~h}\right)$. Peak plasma pantothenate occurred at $2.5 \mathrm{~h}$ and levels over $250 \mu \mathrm{M}$ were seen at 300 times normal. Apparent total body storage of pantothenate was significant $(25 \mathrm{mg} / \mathrm{kg})$, and plasma levels were elevated threefold for months after pantethine therapy. Plasma cysteamine concentrations after pantethine were similar to those reported after equivalent doses of cysteamine. However, at best only $80 \%$ white blood cell cystine depletion occurred. We conclude that pantethine is probably less effective than cysteamine in the treatment of nephropathic cystinosis and should only be considered in cases of cysteamine intolerance. Serum cholesterol was decreased an average of $14 \%$, which supports the potential clinical significance of pantethine as a hypolipemic agent. Rapid in vivo hydrolysis of pantethine suggests that pantothenate or cysteamine may be the effectors of its hypolipemic action.
\end{abstract}

\section{Introduction}

Pantetheine, the amide conjugate of pantothenic acid and cysteamine, occurs naturally as a portion of coenzyme $\mathrm{A}$ and the phosphopantetheine of acyl-carrier protein. These coenzymes are extensively involved in carbohydrate, lipid, and amino acid metabolism (1) and use the terminal thiol of pantetheine for transfer of acyl groups.

Pantethine, the disulfide dimer of pantetheine, has been promoted for clinical use as a hypolipemic agent. It is marketed in Japan (Pantosin; Daiichi Seiyaku Co., Ltd., Tokyo) and Italy

This study was presented in part at the annual meeting of the Midwest Society for Pediatric Research, Chicago, IL, 31 October 1984.

Address reprint requests to Dr. Thoene, Department of Pediatrics, The University of Michigan Medical School, Kresge II, R6032, Ann Arbor, MI 48109. Dr. Wittwer's current address is Dept. of Pathology, University of Utah School of Medicine, Salt Lake City, UT 84132.

Received for publication 20 February 1985.

The Journal of Clinical Investigation, Inc

Volume 76, October 1985, 1665-1672
(Pantetina; Maggioni Farmaceutici SPA, Milano) as a "natural" hypolipemic drug without side effects. Several clinical trials with dyslipidemic patients have shown decreased total serum cholesterol (10-20\%) and triglycerides (15-68\%), with increased high density lipoprotein, cholesterol and apolipoprotein $A_{1}$ levels (211). These beneficial effects are assumed to be secondary to increased levels of intracellular pantothenate coenzymes. Animal studies suggest that pantethine is more effectively conserved and used than pantothenic acid (12). Direct phosphorylation of pantetheine by pantothenate kinase (1) would bypass the first three steps of coenzyme A biosynthesis required when pantothenate is the initial substrate.

A second possible clinical use of pantethine is as a source of cysteamine for the treatment of nephropathic cystinosis $(13,14)$. In this autosomal recessive storage disease (15), cystinotic cells accumulate cystine because of a defective lysosomal membrane transport system $(16,17)$. Cysteamine can deplete intralysosomal cystine in vitro and in vivo (18-20) by a disulfide interchange reaction that produces cysteine and cysteamine-cysteine mixed disulfide (14), both of which can freely leave cystinotic lysosomes. Although cysteamine can be given exogenously, it can also be generated endogenously from pantetheine by the enzyme "pantetheinase" (1, 21-23). Pantethine's depletion of cystine from cystinotic fibroblasts (13) and renal cells in culture (24) is considered secondary to its production of cysteamine (14). Pantethine has very low toxicity $(25,26)$ compared with cysteamine (27) and might serve as a neutral systemic carrier that would target cysteamine intracellularly, avoiding toxicity and maximizing effectiveness. Since the kidney has been considered the principal site of pantethine degradation to cysteamine (12), pantethine might be particularly appropriate for treatment of cystinotic children who often develop kidney failure by $10 \mathrm{yr}$ of age.

Both of the above proposed mechanisms for pantethine's action, i.e., accelerated coenzyme $\mathrm{A}$ biosynthesis and directed cysteamine transport, require that pantethine reach target cells before hydrolysis to pantothenate and cysteamine. Previous investigations of pantethine metabolism in animals (12, 28-32) have differed as to the degree of pantethine hydrolysis that occurs during intestinal absorption. Both predominantly intact absorption (28) and complete hydrolysis (32) have been claimed for the rat. Prior study of pantethine metabolism in humans is limited to a single report (33) on the urinary excretion of pantethine and pantothenate after intramuscular injection with pantethine.

Although derived from and strictly applicable only to cystinotic subjects, much of our data may also represent pantethine metabolism in normal humans. At least one aspect of pantethine metabolism, the activity of pantetheinase in fibroblasts and leukocytes, is normal in cystinotics (23). The isolated molecular defect in cystinosis, an altered lysosomal membrane transport system for cystine, would not be expected to specifically affect pantethine metabolism. Nevertheless, nonspecific effects, such as variable renal failure, require caution in extrapolation. 


\section{Methods}

Protocol. Four cystinotic children were admitted to the Clinical Research Center of the University of Michigan (patients 1, 2, and 4), or the Clinical Center of the National Institutes of Health (patient 3) under protocols approved by the respective Institutional Review Boards with informed consent. D-Pantethine, supplied as a 70\% syrup and diluted to 100-500 $\mathrm{mg} / \mathrm{ml}$, was obtained from the Food and Drug Division of Sigma Chemical Co. (St. Louis, MO) under a Notice of Claimed Investigational Exemption for a New Drug.

Cysteamine was withheld from all subjects for at least $5 \mathrm{~d}$ before admission to allow reaccumulation of leukocyte cystine. A nonrestricted ad lib. diet was maintained that did not vary noticeably during the course of pantethine administration. Base-line laboratory tests, repeated before discharge, included a complete blood count with leukocyte differential, serum electrolytes, liver function tests, blood urea nitrogen, creatinine, fasting cholesterol, triglycerides, and high density lipoprotein cholesterol.

D-Pantethine was administered orally as an aqueous solution every $6 \mathrm{~h}$ in equally divided doses totaling $70-1,000 \mathrm{mg} / \mathrm{kg}$ per $\mathrm{d}(0.25-3.6$ $\mathrm{meq} / \mathrm{kg}$ per d). Each dose was maintained for $48 \mathrm{~h}$ and was followed by an increase in dosage. Blood samples for measurement of leukocyte cystine, and plasma cysteamine, pantothenate, and pantethine were obtained 1 and $5 \mathrm{~h}$ after the last dose at a particular level. Urine was collected during the last $24 \mathrm{~h}$ of a particular dosage interval for measurement of pantothenate, pantethine, inorganic sulfate, and total sulfur. Individual variations in protocols are given below under the patient descriptions.

Cystinotic subjects. Patient 1 was a 6-yr-old white female who had tolerated cysteamine therapy well for the previous $4 \mathrm{yr}$. Her weight was $17 \mathrm{~kg}$, creatinine clearance $67 \mathrm{ml} / \mathrm{min}$ per $1.73 \mathrm{~m}^{2}$, and initial leukocyte cystine (after reaccumulation) $6.6 \mathrm{nmol} / \mathrm{mg}$ protein. On her first admission she received the following doses of pantethine: 70, 140, 210, 280, and $350 \mathrm{mg} / \mathrm{kg}$ per $\mathrm{d}$. On her second admission $6 \mathrm{mo}$ later, she received a single $62-\mathrm{mg} / \mathrm{kg}$ dose followed by $2-\mathrm{d}$ courses of 500 and then 1,000 $\mathrm{mg} / \mathrm{kg}$ per d pantethine.

Patient 2, a 14-yr-old white male with intermediate cystinosis, had received cysteamine for $1 \mathrm{yr}$ but tolerated it poorly, with lethergy, nausea, and vomiting. His weight was $46 \mathrm{~kg}$, creatinine clearance $37 \mathrm{ml} / \mathrm{min}$ per $1.73 \mathrm{~m}^{2}$, and initial leukocyte cystine $3.7 \mathrm{nmol} / \mathrm{mg}$ protein. On his first admission, he received the following doses of pantethine: 70, 280, 350, 500 , and $700 \mathrm{mg} / \mathrm{kg}$ per $\mathrm{d}$. His second admission followed the first by 3 mo. He received a single $32-\mathrm{mg} / \mathrm{kg}$ dose followed by a $2-\mathrm{d}$ course of 500 $\mathrm{mg} / \mathrm{kg}$ per $\mathrm{d}$ pantethine. He then received $1,000 \mathrm{mg} / \mathrm{kg}$ per $\mathrm{d}$ for the next $18 \mathrm{~d}$ as an outpatient.

Patient 3, a 10-yr-old white male, had discontinued cysteamine treatment 6 mo before admission due to liver disease. The particulars of his case have been described $(34,35)$. His weight was $18 \mathrm{~kg}$, creatinine clearance $17 \mathrm{ml} / \mathrm{min}$ per $1.73 \mathrm{~m}^{2}$, and initial leukocyte cystine $7.5 \mathrm{nmol} / \mathrm{mg}$ protein. On his first admission, he received the following doses of pantethine: $70,140,210$, and $350 \mathrm{mg} / \mathrm{kg}$ per $\mathrm{d}$. During his second admission $3 \mathrm{mo}$ later, he received $350 \mathrm{mg} / \mathrm{kg}$ per d of pantethine for four consecutive days.

Patient 4 was a 10-yr old white male treated with cysteamine for 6 yr who experienced occasional nausea and vomiting. His weight was 23 $\mathrm{kg}$, creatinine clearance $19 \mathrm{ml} / \mathrm{min}$ per $1.73 \mathrm{~m}^{2}$, and initial leukocyte cystine $7.8 \mathrm{nmol} / \mathrm{mg}$ protein. He received $250 \mathrm{mg} / \mathrm{kg}$ per d pantethine for the first $2 \frac{1}{2} \mathrm{~d}$ at the usual schedule of one dose every $6 \mathrm{~h}$. His schedule was then changed to three times a day with meals, with the following increasing doses of pantethine: 250,500 , and $1,000 \mathrm{mg} / \mathrm{kg}$ per d.

Assays. Heparinized blood was centrifuged in the cold and plasma frozen in a $\mathrm{CO}_{2}$ acetone bath. Plasma and urinary pantothenate were measured by radioimmunoassay (with antisera supplied by Dr. Bonita W. Wyse, Utah State University, UT) (36) after protein precipitation with $\mathrm{Ba}(\mathrm{OH})_{2}$ and $\mathrm{ZnSO}_{4}$ (37). Plasma pantethine was calculated as the difference between free pantothenate and total pantothenate after hydrolysis with pantetheinase (21). Plasma was incubated for $1 \mathrm{~h}$ at $37^{\circ} \mathrm{C}$ in $10 \mathrm{mM}$ Tris- $\mathrm{HCl}, \mathrm{pH} 8.5$, with $5 \mathrm{mM}$ dithiothreitol and $20 \mathrm{mU}$ of pantetheinase (supplied by Dr. R. Gaurth Hansen, Utah State University, $\mathrm{UT})^{1}$ per $\mathrm{ml}$ of plasma. By this method, $97 \%$ of pantethine added to plasma and $96 \%$ of pantethine added to urine were recovered as pantothenate. Neither plasma ( 32 samples) nor urine ( 17 samples) exhibited any pantethine by this method; however, prior removal of pantothenate from urine samples by ion exchange allowed a more sensitive assay for urinary pantethine. Over $99 \%$ of the pantothenate in $0.5 \mathrm{ml}$ of urine could be removed by passing it through a $0.7 \times 2-\mathrm{cm}$ column of Dowex $1 \times 4\left(\mathrm{OH}^{-}\right.$form, $\left.100-200 \mathrm{mesh}\right)$ and washing it with $4.5 \mathrm{ml}$ of water. The eluant was neutralized with phosphate buffer and pantethine was measured as the difference between free and total pantothenate as above. The recovery of pantethine by this method was $\sim 80 \%$.

Plasma cysteamine was measured by reaction with radiolabeled cystine thiosulfonate and separation by high voltage electrophoresis (38). Urinary inorganic sulfate was determined by turbidimetry of barium sulfate, and total sulfur by prior wet oxidation with nitric and perchloric acids in the presence of vanadate as catalyst (39). Recovery of sulfur from pantethine by this procedure was $96 \%$.

Leukocytes, harvested by dextran sedimentation and hypotonic lysis of red blood cells (40), were lysed by brief sonication and protein-precipitated in sulfosalicylic acid (final concentration, 3\%). Cystine in the supernatant was measured by a competitive binding assay (41). Protein was measured with Folin's phenol reagent (42) with bovine serum albumin as standard.

Supernatants of random stool samples were analyzed for osmolality and electrolytes by the hospital laboratory, and for total sulfur, cysteamine, pantothenate, and pantethine by the methods described above.

Excess small bowel biopsy material from a 10-yr-old boy (kindly supplied by Dr. William Byrne, University of Michigan, MI) with malabsorption was obtained, which was later histologically identified as normal. The sample was immediately homogenized in 4 vol of cold 0.02 $\mathrm{M}$ Tris- $\mathrm{HCl}, \mathrm{pH}$ 8.2. Pantetheinase activity was measured by the pantothenate assay (43), modified as follows: $40 \mu \mathrm{g}$ of mucosal protein was incubated with 1 meq of dithiothreitol and 1,2 , or 11 meq of pantethine in $0.05 \mathrm{M} \mathrm{Tris}-\mathrm{HCl}, \mathrm{pH} 8.2$, for $80 \mathrm{~min}$ at $37^{\circ} \mathrm{C}$ in a total volume of $100 \mu \mathrm{l}$.

Male Sprague-Dawley rats were killed by decapitation and small intestinal mucosa were scraped off with a glass rod. The mucosal samples were homogenized in $4 \mathrm{vol}$ of cold $0.02 \mathrm{M}$ Tris- $\mathrm{HCl}, \mathrm{pH} \mathrm{8.2.} 25 \mu \mathrm{l}$ of the homogenate was prereduced and enzyme activity was determined according to the pantothenate assay (43). Glycine- $\mathrm{HCl}$, acetate, phosphate, Tris- $\mathrm{HCl}$, and carbonate buffers were used at $0.25 \mathrm{M}$ final concentration to measure activity between $\mathrm{pH} 2$ and 10. Double reciprocal plots of kinetic data were used for Michaelis constant $\left(K_{\mathrm{m}}\right)$ determination.

Statistical analysis employed the $t$ test on the paired percentage difference of values. Since analysis of the first 13 pairs of 1 - and 5-h postdose plasma samples revealed no significant difference between paired values in terms of pantothenate $(P>0.05)$, cysteamine $(P>0.3)$, and leukocyte cystine $(P>0.2)$ concentrations, the 1 - and 5 -h values were averaged.

\section{Results}

Intestinal pantetheinase. Pantetheine-degrading activity was detected in both rat and human intestine. The $\mathrm{pH}$ profile for rat intestinal pantetheinase showed a broad plateau between $\mathrm{pH} 4$ and 9, and the enzyme followed Michaelis-Menten kinetics with a $K_{\mathrm{m}}$ of $4.6 \mu \mathrm{M}$ (data not shown). Human small intestinal mucosa had a pantetheinase specific activity of $1.2 \mathrm{nmol} / \mathrm{min}$ per $\mathrm{mg}$ protein and showed inhibition by excess pantethine. When the ratio of pantethine to pantetheine (pantethine reduced by dithiothreitol) in the reaction mixture was increased from 0 to 1 to 10 , enzymatic activity decreased from 100 to 79 to $70 \%$, respectively. Known properties of pantetheinase from different tissues are given in Table I.

1. A unit of enzyme is defined as the amount that would produce $1 \mu \mathrm{mol}$ pantothenate/min under the conditions of the mercaptide assay (43). 
Table I. Properties of Pantetheinase from Different Tissues

\begin{tabular}{|c|c|c|c|}
\hline Tissue & $\begin{array}{l}\text { Homogenate } \\
\text { specific } \\
\text { activity }\end{array}$ & $K_{\mathrm{m}}$ & pH Optima \\
\hline & $\begin{array}{l}n m o l / m i n ~ p e r \\
m g \text { protein }\end{array}$ & $\mu M$ & \\
\hline Pig kidney (41) & 2.5 & 20 & $9.0-9.5$ \\
\hline Plasma* & 0.16 & 7.0 & 7 \\
\hline $\begin{array}{l}\text { Small intestinal } \\
\text { mucosa }\end{array}$ & 1.2 & 4.6 (rat) & 4-9 (rat) \\
\hline Leukocytes & & & \\
\hline (23) & 0.87 & 440 & $6.5-7.5$ \\
\hline Fibroblasts (23) & 0.04 & 110 & $6-7$ \\
\hline
\end{tabular}

Tissues are human unless otherwise specified.

* Song, W. O., personal communication.

For the four subjects receiving oral pantethine, plasma pantethine was undetectable with the assay method used. The pantethine assay has a detectability limit of 5-10\% of the concurrent pantothenate concentration, which indicates extensive hydrolysis of pantethine on absorption. Urinary pantethine averaged $0.57 \pm 0.32 \%$ (SD) of the pantothenate excreted $(n=23)$.

Pantothenate pharmacokinetics. For two different subjects receiving a single dose of oral pantethine, plasma pantothenate concentration peaked after $\sim 2.5 \mathrm{~h}$ (Figs. 1 and 2 ). The curves are consistent with an "open two-compartment" model (44) of pantothenate pharmacokinetics. Resolution of log linear components in Fig. 2 by the method of residuals (44) gives exponential rate constants $(k)$ of the form $C=C_{0} e^{-k t}$, with values of 1.6/h (absorption), 1.2/h (distribution), and $0.025 / \mathrm{h}$ (elimination). Only $2.5 \%$ of the administered pantethine was excreted as pantothenate within the first $24 \mathrm{~h}$.

Initial plasma pantothenate concentrations were $0.39,0.61$, 1.8 , and $1.5 \mu \mathrm{M}$, for patients $1,2,3$, and 4 , respectively. During pantethine treatment, plasma pantothenate levels rose to $>250$ $\mu \mathrm{M}$ (Fig. 3). Long after pantethine treatment had ended, plasma pantothenate remained elevated (1.3 $\mu \mathrm{M}$ after 6 mo for patient

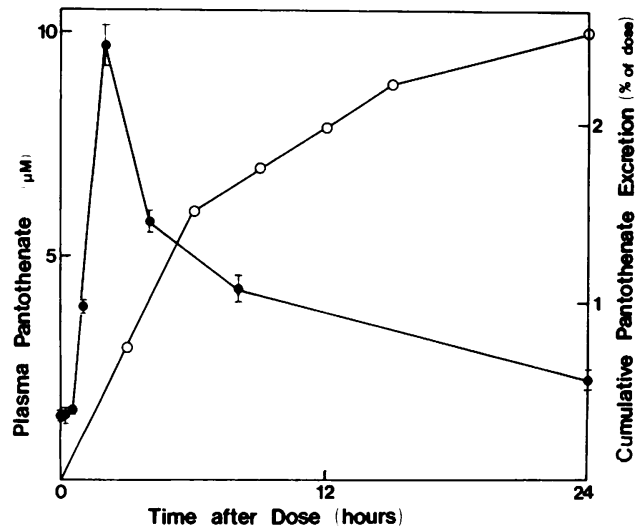

Figure 1. Cumulative urinary excretion and plasma concentration of D-pantothenate after a single $0.12-\mathrm{meq} / \mathrm{kg}(32 \mathrm{mg} / \mathrm{kg})$ oral dose of Dpantethine in patient 2 . This intermediate cystinotic had been treated $3 \mathrm{mo}$ earlier with up to $700 \mathrm{mg} / \mathrm{kg}$ per d pantethine (see Methods). Plasma concentration ( $\bullet$ SEM of 5-15 assays) and cumulative urinary excretion $(0)$ of pantothenate were measured by radioimmunoassay (36).

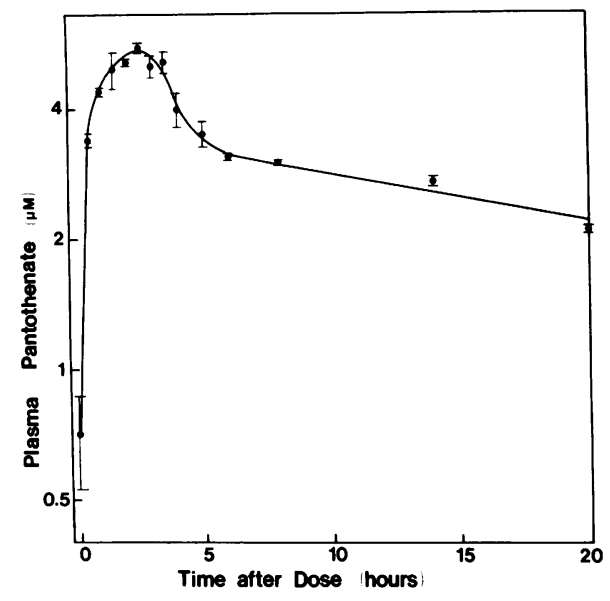

Figure 2. Plasma concentration of pantothenate after a single 0.22 $\mathrm{meq} / \mathrm{kg}(62 \mathrm{mg} / \mathrm{kg})$ oral dose of pantethine in patient 1 . She had been treated 6 mo earlier with up to $350 \mathrm{mg} / \mathrm{kg}$ per d pantethine (see Methods). No pantethine could be detected in plasma. Values are given as a mean \pm SEM for two to five assays. Note logarithmic scale.

1 and $1.8 \mu \mathrm{M}$ after 3 mo for patient 2). Plasma pantothenate concentrations correlated poorly with pantethine dose (data not shown). However, when plasma pantothenate was plotted against the cumulative pantethine dose, each subject's values fell onto one of two curves (Fig. 3).

Pantothenate excretion was also highly dependent on the cumulative dose of pantethine (Fig. 4). The initial excretion $(<2 \%)$ increased with time and leveled off at $\sim 8 \%$ of the dose. Patient 2 was excreting $6 \%$ of the pantothenate present in his pantethine dose after an $18-\mathrm{d}$ course of $1,000 \mathrm{mg} / \mathrm{kg}$ per $\mathrm{d}$. At low plasma pantothenate levels, pantothenate clearance was ap-

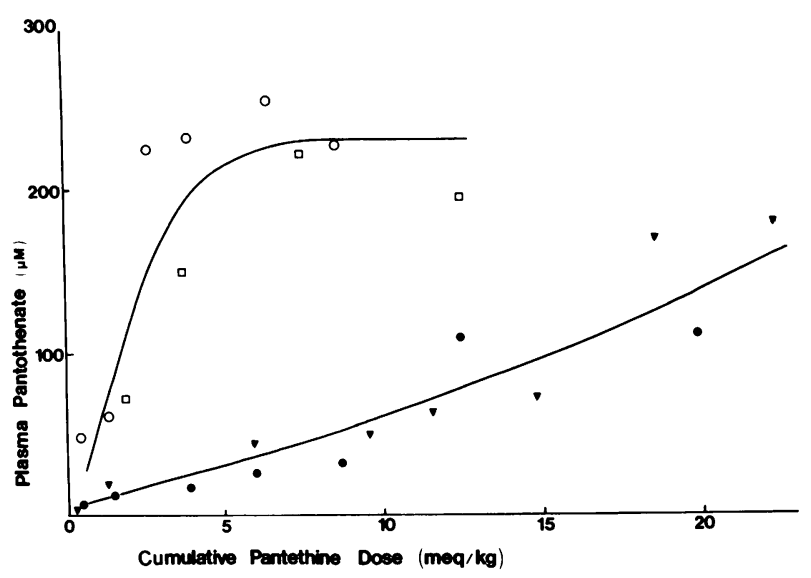

Figure 3. Two apparently distinct curves of plasma pantothenate response to cumulative pantethine dose. Patients were treated with 70 $1,000 \mathrm{mg} / \mathrm{kg}$ per d $(0.25-3.6 \mathrm{meq} / \mathrm{kg}$ per d) oral D-pantethine administered in four equally divided doses given every $6 \mathrm{~h}$. Each dose was maintained for $48 \mathrm{~h}$ and was followed by an increase in dosage. Treatment periods ranged from 4 to $10 \mathrm{~d}$ (see Methods). Patient 1 (๑), patient $2(\nabla)$, and patient $3(0)$ were studied on two separate admissions. The summation of pantethine dosage (expressed as the abscissa) is continuous, even between these dual admissions. Patient 4 ( $\square$ ) was studied only once. Plasma samples obtained 1 and $5 \mathrm{~h}$ after the last dose at a particular level were analyzed for pantothenate and averaged. 


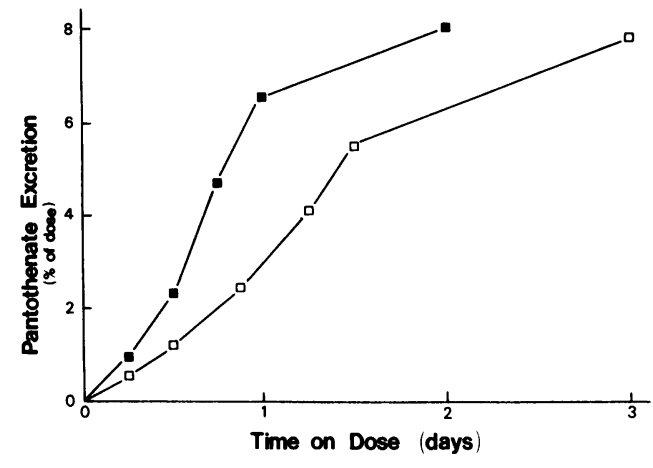

Figure 4. Dependence of pantothenate excretion upon duration at a given pantethine dose. At time zero, patients were begun on either 500 $\mathrm{mg} / \mathrm{kg}$ per d (patient $1, \boldsymbol{a}$ ) or $250 \mathrm{mg} / \mathrm{kg}$ per d (patient $4, \square$ ) pantethine. Patient 1 had been treated 6 mo earlier with up to $350 \mathrm{mg} / \mathrm{kg}$ per d pantethine (see Methods) and had received a single $62-\mathrm{mg} / \mathrm{kg}$ dose $24 \mathrm{~h}$ before the initiation of the current study. Her plasma pantothenate concentration at time zero was $2.1 \mu \mathrm{M}$. Patient 4 had not been treated previously with pantethine, but did chronically take vitamin supplements containing $10 \mathrm{mg}$ calcium pantothenate/d. His initial plasma pantothenate concentration was $1.5 \mu \mathrm{M}$. Serial urine collections were taken and analyzed for pantothenate by radioimmunoassay (36).

proximately half the creatinine clearance (Fig. 5). However, between 20 and $60 \mu \mathrm{M}$ pantothenate, the fractional excretion of pantothenate was well above 1 , while above $60 \mu \mathrm{M}$, pantothenate clearance decreased to that of creatinine.

Cysteamine and cystine metabolism. Plasma cysteamine concentration increased with pantethine dose in a similar manner for three of the four subjects (Fig. 6). When organic sulfur excretion (the difference between total sulfur and inorganic sulfate excretion) was plotted against pantethine dose, a similar rapid rise, followed by a plateau, was seen (data not shown). Inorganic sulfate excretion varied in a biphasic manner with pantethine dose (Fig. 7)

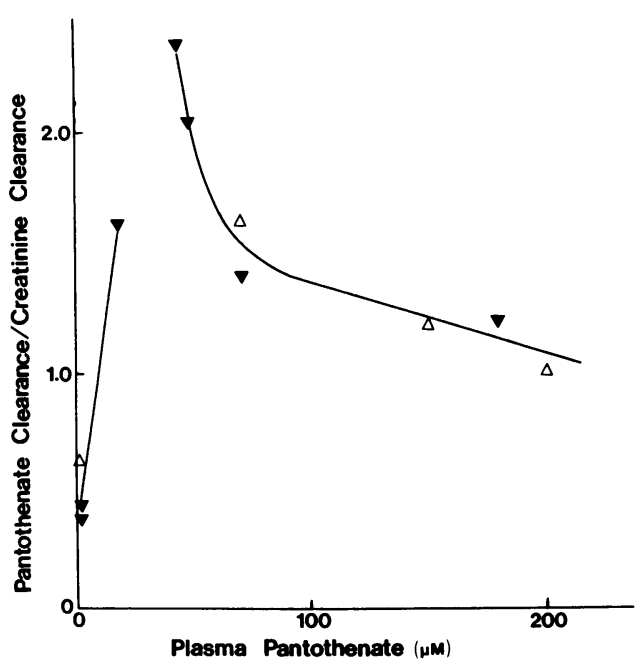

Figure 5. Dependence of the fractional excretion of pantothenate on the concentration of plasma pantothenate. Protocols of pantethine treatment were the same as in Fig. 3. Urine was collected during the last $24 \mathrm{~h}$ of treatment at a particular dose. Plasma pantothenate was sampled at the end of these collections and used to calculate pantothenate clearances. Patient $2(\nabla)$ and patient $4(\Delta)$ were included.

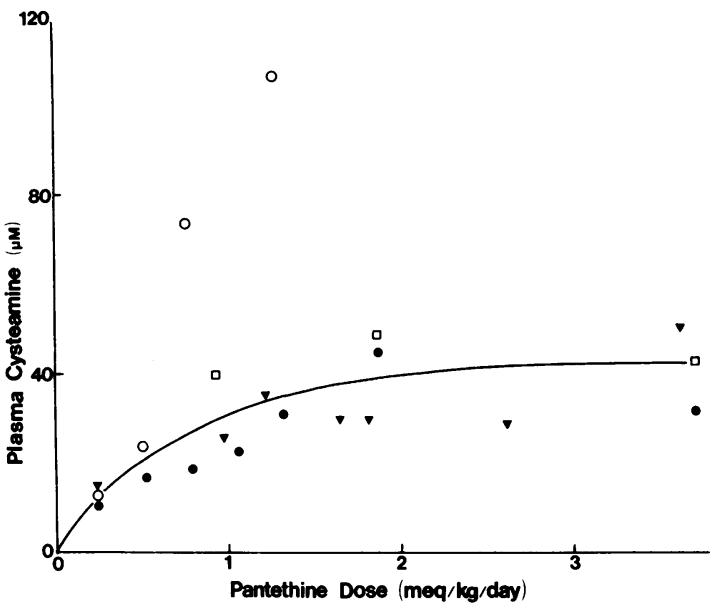

Figure 6. Plasma cysteamine dependence on pantethine dose. Protocols of pantethine treatment were the same as in Fig. 3. Plasma samples obtained 1 and $5 \mathrm{~h}$ after the last dose at a particular level were analyzed for cysteamine (38) and averaged. Patient symbols are the same as in Fig. 3.

Fig. 8 shows the time variation of plasma pantothenate, plasma cysteamine, and leukocyte cystine depletion on different doses and dosage schedules of oral pantethine. Plasma pantothenate remained nearly constant for $6 \mathrm{~h}$ and plasma cysteamine for $4 \mathrm{~h}$ after a dose. Administering $250 \mathrm{mg} / \mathrm{kg}$ per d pantethine three times a day with meals, as opposed to every $6 \mathrm{~h}$, doubled plasma pantothenate, increased plasma cysteamine, and increased leukocyte cystine depletion. Increasing the dose to 1,000 $\mathrm{mg} / \mathrm{kg}$ per $\mathrm{d}$ did not alter plasma cysteamine and appeared to decrease leukocyte cystine depletion.

Leukocyte cystine depletion correlated poorly with pantethine dose (Fig. $9 \mathrm{~A}$ ) but reasonably well with plasma cysteamine (Fig. $9 \mathrm{~B}$ ). The maximum leukocyte cystine depletion achieved was $80 \%$.

Clinical side effects. No serious side effects were seen with pantethine treatment. Base-line laboratory tests, including liver function tests, were not changed appreciably, except that fasting serum cholesterol (initial range, $212-253 \mathrm{mg} / \mathrm{dl}$ ) decreased an average of $14.3 \%$ (final range, $189-210 \mathrm{mg} / \mathrm{dl}$ ). One patient preferred pantethine's bitter taste to cysteamine, and another found the two drugs "different, but both just as bad."

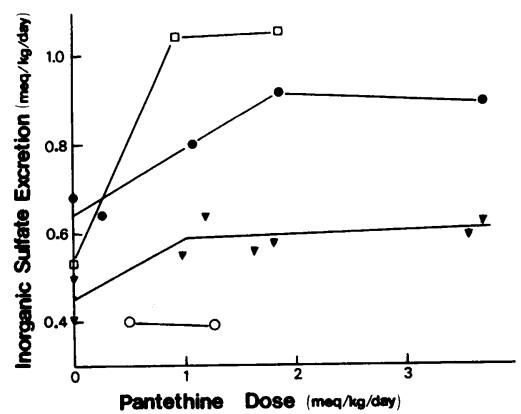

Figure 7. The effect of pantethine dose on inorganic sulfate excretion. Protocols of pantethine treatment were the same as in Fig. 3. Urine was collected during the last $24 \mathrm{~h}$ of treatment at a particular dose and inorganic sulfate was determined by turbidimetry of barium sulfate (39). Patient symbols are the same as in Fig. 3. 

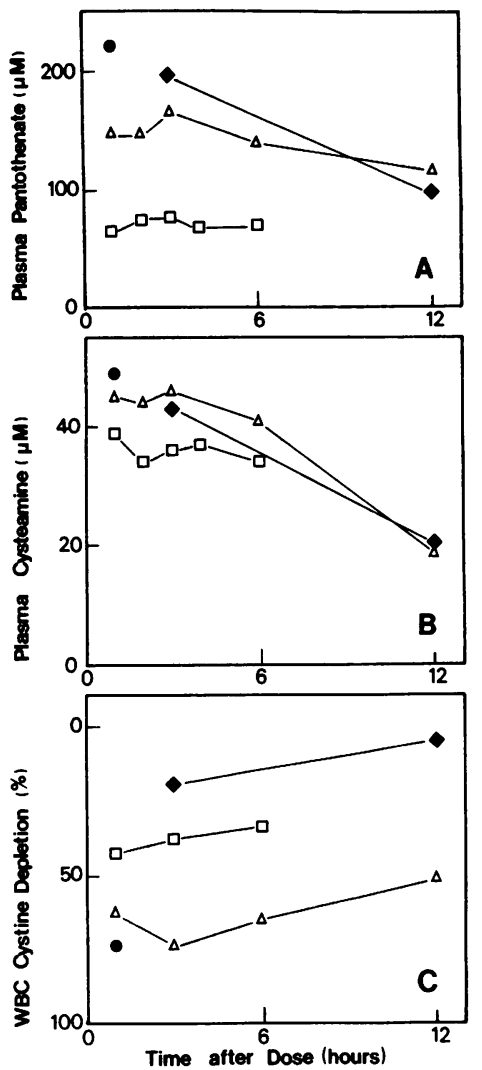

Figure 8. Time variation of plasma pantothenate $(A)$, plasma cysteamine $(B)$, and leukocyte cystine depletion $(C)$ at selected doses and dosage schedules of pantethine for patient $4 . \mathrm{He}$ initially received $250 \mathrm{mg} / \mathrm{kg}$ per $d$ oral D-pantethine for the first $2 \frac{1}{2} d$ at the usual schedule of one dose every $6 \mathrm{~h}$ (口). His schedule was then changed to three times a day with meals, and he was sequentially treated with the following doses of pantethine: $250(\Delta), 500(\bullet)$, and $1,000(\bullet) \mathrm{mg} / \mathrm{kg}$ per $\mathrm{d}$, each for $2 \mathrm{~d}$. Blood samples were drawn after the last dose of each treatment period.

Diarrhea consistently occurred at doses above $350 \mathrm{mg} / \mathrm{kg}$ per $\mathrm{d}$ and was marked at $1,000 \mathrm{mg} / \mathrm{kg}$ per $\mathrm{d}$. In one such stool supernatant, only $32 \%$ of the total osmolality ( 335 mosM) was accounted for by the usual electrolytes, i.e., $\left(\left[\mathrm{Na}^{+}\right]+\left[\mathrm{K}^{+}\right]\right)$ $\times 2$. Pantethine, pantothenate, and cysteamine accounted for

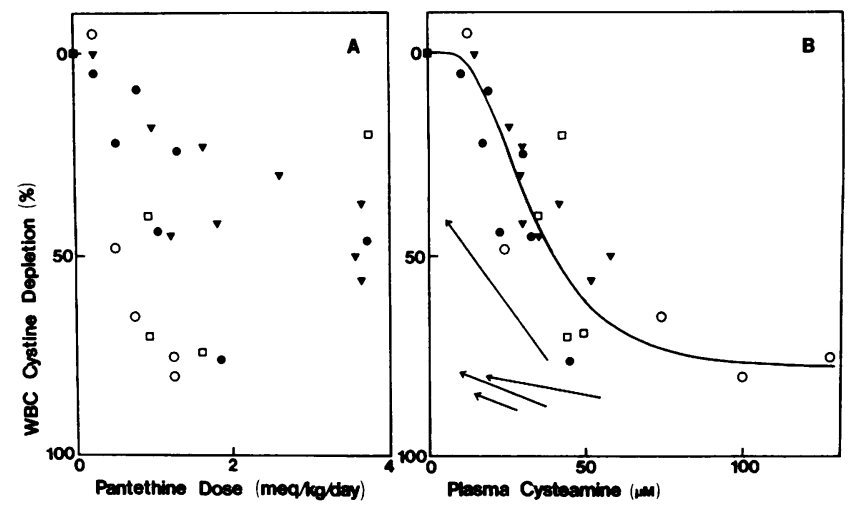

Figure 9. Leukocyte cystine depletion with pantethine therapy. Patients were given $70-1,000 \mathrm{mg} / \mathrm{kg}$ per $\mathrm{d}(0.25-3.6 \mathrm{meq} / \mathrm{kg}$ per d) oral pantethine in four equally divided doses given every $6 \mathrm{~h}$. Each dose was maintained for $48 \mathrm{~h}$ and was followed by an increase in dosage. Treatment periods ranged from 4 to $10 \mathrm{~d}$ (see Methods). Leukocyte cystine and plasma cysteamine were determined from blood samples obtained 1 and $5 \mathrm{~h}$ after the last dose at a particular level and averaged. Depletion values are plotted against pantethine dose $(A)$ and plasma cysteamine concentration $(B)$. Patient symbols are the same as in Fig. 3. The arrows in $B$ represent data taken from Jonas and Schneider (45) for cystinotic children treated with oral cysteamine. The arrow tails were sampled at $1 \mathrm{~h}$ after a dose, while the arrow heads were sampled $6 \mathrm{~h}$ after a dose.
$83 \%$ of the remaining osmoles. Random stool samples from patients 1 and 4 indicated that at $1,000 \mathrm{mg} / \mathrm{kg}$ per $\mathrm{d}, \sim 62 \%$ of administered pantethine was not absorbed or hydrolyzed in the intestinal tract. The remainder was apparently hydrolyzed, but another $24 \%$ of the pantothenate and $14 \%$ of the cysteamine present in the original dose of pantethine were not absorbed. The stool $\mathrm{pH}$ was 5.5-6.0.

\section{Discussion}

After high doses of oral pantethine, plasma pantothenate levels were elevated to 300 times normal, and plasma cysteamine levels were comparable to those found after oral cysteamine therapy (45). However, no pantethine (or pantetheine) could be detected in plasma, which indicated levels $<5-10 \%$ of the plasma pantothenate concentration. Although the extent to which pantethine is hydrolyzed at the intestinal wall is uncertain, recent animal experiments favor nearly complete hydrolysis (32). Intestinal pantetheinase has the lowest $K_{\mathrm{m}}$ of this enzyme for any measured tissue (Table I). Any panteth(e)ine surviving passage through the intestinal wall would next contact plasma pantetheinase. Assuming substrate saturation, this enzyme circulated at levels sufficient to produce the highest plasma pantothenate concentration observed in this study in $<30 \mathrm{~min}$. We conclude that pantethine is hydrolyzed before distribution to tissues and cannot be used to target cysteamine intracellularly for an increased therapeutic ratio in the treatment of nephropathic cystinosis.

However, since a small fraction $(<1 \%)$ of pantothenate is excreted as pantethine, some pantethine may circulate transiently. This fraction could account for the hypolipemic effect of pantethine. In perfused rat liver, pantethine is a more effective precursor of coenzyme A than pantothenate (46). Alternatively, either pantothenate or cysteamine could be responsible for pantethine's hypolipemic action. Cysteamine has numerous pharmacologic actions (21) and hormonal effects $(47,48)$. Pantothenate deficiency has been reported to lower blood cholesterol levels in the rat (49) and $\operatorname{dog}(50)$, but this was not demonstrated in humans (51). We know of no reports investigating hypolipemic properties of cysteamine or pantothenate.

We have confirmed that pantethine is nontoxic and may be more palatable than cysteamine in some patients with nephropathic cystinosis. No serious side effects were encountered, even though doses up to 70 times those currently employed for hyperlipemia were used (2-11). In particular, no elevation of liver function tests occurred (52). An osmotic diarrhea did occur at doses above $350 \mathrm{mg} / \mathrm{kg}$ per $\mathrm{d}$. Absorption was severely limited at high doses, and pantethine, pantothenate, and cysteamine were the major osmotic agents. Most of the pantethine was neither absorbed nor hydrolyzed when given at a dose of $1,000 \mathrm{mg} /$ kg per $\mathrm{d}$.

The exact cause of the poor absorption is uncertain. Most likely, the absorptive capacity of the intestine is overwhelmed by pharmacologic doses of an agent usually present only in trace quantities. Delaying the transit time by giving the drug with meals did increase absorption (Fig. 8). The acidic stool pH (5.56.0) could be a contributing factor to poor absorption. The hydrolysis of pantetheine does produce some acid at neutral $\mathrm{pH}$ (43). However, the stool osmolality was also elevated (335 mosM), and both these changes may simply represent continued bacterial metabolism outside of the body. Like pantetheinase from other tissues $(1,21-23)$, intestinal pantetheinase requires 
a reducing environment for full activity. When human intestinal mucosa was incubated with increasing amounts of oxidized pantethine, inhibition of pantetheinase occurred. Perhaps excess pantethine overloads the capacity of the intestine for pantethine reduction to pantetheine (53). The oxidizing intraluminal milieu would inhibit pantetheinase, hydrolysis and absorption would decrease, and an osmotic diarrhea would occur.

Our data suggest significant total body storage of pantothenate. Pharmacokinetic studies of pantothenate (Figs. 1 and 2) reveal rapid absorption and distribution, with slow excretion $\left(t_{1 / 2}=28 \mathrm{~h}\right)$. Limited excretion after pantothenate loading has been previously reported $(12,33,54)$. Fig. 1 indicates 24 -h excretion of only $2.5 \%$ after a single dose. Fig. 4 is most readily interpreted by assuming a constant pantothenate absorption of $\sim 8 \%$ with a sigmoid increase in excretion that indicates a gradual saturation of pantothenate stores. Initially, most of the absorbed pantothenate would be stored and not excreted. Only with total body saturation would the amount excreted approach the amount absorbed. If the abscissa of Fig. 4 is expressed in terms of the cumulative pantethine dose, the area above each curve (but below $8 \%$ excretion) can be used to quantitate pantothenate storage. Integration of the difference between absorption and excretion gives a value of $\sim 25 \mathrm{mg}$ pantothenate $/ \mathrm{kg}$ body $\mathrm{wt}$. The amount of pantothenate carried by the plasma is a small fraction of total body storage, and our estimate of pantothenate storage should be valid despite variations in renal function and its possible effect on plasma pantothenate concentration. Indeed, similar values were obtained for both patients in Fig. 4, even though they had widely different creatinine clearances (67 and $19 \mathrm{ml} / \mathrm{min}$ per $1.73 \mathrm{~m}^{2}$ ).

The fact that plasma pantothenate correlates best with cumulative pantethine dose (Fig. 3) also supports significant pantothenate storage. It appears that plasma pantothenate concentration is determined more by chronic total pantothenate load than by current dosage. Absorption and distribution of any given dose are rapid, but excretion of total body stores is slow. Our samples were measured 1 and $5 \mathrm{~h}$ after a dose, away from the peak levels expected at $2.5 \mathrm{~h}$ (Figs. 1 and 2). Plasma pantothenate was elevated to three times initial values months after pantethine treatment, which indicates continued replacement of pantothenate in the plasma compartment with tissue stores. Storage of pantothenate has previously been suspected $(55,56)$. The significance of these findings in terms of functional pantothenate status and coenzyme activity are unknown.

The segregation of subjects onto one of two curves in Fig. 3 is curious. The different responses could indicate initial differences in pantothenate stores. Patients 3 and 4 had higher initial plasma pantothenate levels than patients 1 and 2, and patient 4 had chronically received $10 \mathrm{mg}$ calcium pantothenate/d as a vitamin supplement before the study. An alternative explanation is that both patients 3 and 4 had significant renal insufficiency (both with a creatinine clearance of $<20 \mathrm{ml} / \mathrm{min}$ per $1.72 \mathrm{~m}^{2}$ ), and pantothenate was retained in the plasma compartment secondary to a decreased filtration.

The tubular secretion and reabsorption of pantothenic acid in rat kidney have recently been studied (57). Net reabsorption occurred when plasma pantothenate was below $15 \mu \mathrm{M}$ and net secretion occurred above $15 \mu \mathrm{M}$. The secretory process was saturable and inhibited by penicillin. Fig. 5 reveals a similar renal handling of pantothenate in cystinotic subjects. At extreme pantothenate concentrations, pantothenate clearance approaches creatinine clearance, which indicates saturation of the secretory mechanism. Since the fractional excretion of pantothenate is plotted in Fig. 5, variation in renal function is nullified, and extrapolation to normal humans should be justified.

Plasma cysteamine concentrations plateau with increasing pantethine dose (Fig. 6), which indicates limited intestinal hydrolysis of pantethine (and hence limited production of cysteamine) at higher doses. The osmotic diarrhea at higher pantethine loads begins to occur just where the curve significantly levels off. The aberrant subject (patient 3 ) had not been treated with cysteamine for the past $6 \mathrm{mo}$, which perhaps indicates that cysteamine metabolism is induced only after chronic intake. Alternatively, his liver disease $(34,35)$ may have impaired cysteamine metabolism.

Orally administered cysteamine is excreted as organic sulfur; significant metabolism to inorganic sulfate does not occur (18). Plots of organic sulfur excretion against pantethine dose were highly variable, perhaps due to dietary intake that was not stringently controlled (data not shown). Nevertheless, a trend to plateau in much the same way as plasma cysteamine was present, which supports limited absorption of cysteamine at higher doses of pantethine.

In contrast to cysteamine, the major end products of cystine in humans are inorganic sulfate and taurine (15). Taurine excretion in cystinotic patients treated with cysteamine is low in comparison with inorganic sulfate excretion (18). Therefore, inorganic sulfate excretion should follow cystine degradation and reflect total body cystine labilization. Indeed, inorganic sulfate excretion did increase with pantethine treatment (Fig. 7), perhaps as a result of cystine depletion and degradation. Increasing the dosage of pantethine beyond a certain point did not further increase inorganic sulfate excretion, which reflects limited cysteamine absorption. There was much variability between patients, both in base-line inorganic sulfate excretion and in the rise seen with pantethine treatment. Base-line variance may be due to differences in dietary intake. The variable increase with pantethine treatment seems to correlate with the initial leukocyte cystine level. The higher the initial cystine load (as reflected by pretreatment leukocyte cystine), the greater the labilization of cystine with pantethine treatment (as reflected by increased inorganic sulfur excretion). The possibility of using inorganic sulfate excretion to test the efficacy of alternative cystine-depleting drugs in cystinosis should not be overlooked.

Pantethine absorption was apparently increased by administering the drug three times a day with meals instead of every $6 \mathrm{~h}$ (Fig. 8). Food may increase or decrease drug bioavailability (58); increased absorption of pantethine may have resulted from increased transit time and prolonged exposure to intestinal pantetheinase. Pantethine doses higher than $250 \mathrm{mg} / \mathrm{kg}$ per $\mathrm{d}$ did little to increase plasma levels of pantothenate and cysteamine (Fig. 8). The decreased leukocyte cystine depletion at $1,000 \mathrm{mg} /$ $\mathrm{kg}$ per $\mathrm{d}$ as compared with $500 \mathrm{mg} / \mathrm{kg}$ per d may be related to the marked diarrhea observed at the higher dose. We did not control for potential sequence effects and day-to-day variation in Fig. 8. Although we do not expect serious artifacts, interpretation should be cautious.

Leukocyte cystine depletion is the conventional indicator of drug effectiveness in the treatment of cystinosis. Cysteamine can deplete $>90 \%$ of leukocyte cystine $(18,20)$, and therapy is aimed at reducing leukocyte cystine levels to those of clinically unaffected heterozygotes (15). Treatment with pantethine did reduce leukocyte cystine (Fig. $9 \mathrm{~A}$ ), but the results were variable and in no case was $>80 \%$ depletion achieved. Differences in absorption 
probably explain the poor correlation of leukocyte cystine depletion with pantethine dose. Better correlation was obtained by plotting leukocyte cystine depletion against plasma cysteamine (Fig. $9 \mathrm{~B}$ ).

Plasma cysteamine concentrations were similar after equivalent doses of pantethine or cysteamine (Fig. 6 and reference 44). However, at equal plasma cysteamine concentrations, oral cysteamine was more effective than pantethine at depleting leukocytes of cystine (Fig. $9 \mathrm{~B}$ ). The explanation is not entirely clear, but we suspect oral cysteamine results in higher peak plasma levels. The production of cysteamine from pantethine was limited by the rate of enzymatic hydrolysis. A brief but extreme peak exposure to cysteamine may be more effective at initiating the disulfide exchange required for leukocyte cystine depletion than the relatively constant infusion of cysteamine produced by intestinal pantethine hydrolysis.

Since oral pantethine cannot produce the leukocyte cystine depletion that cysteamine can, we do not recommend its use in nephropathic cystinosis and have discontinued clinical trials. However, it might still be useful in cases of cysteamine intolerance. Another option, currently being investigated, is the use of phosphocysteamine (59).

\section{Acknowledgments}

We thank the staff of the Clinical Research Unit, University of Michigan, for excellent care of the patients, Dr. Craig B. Langman of MichaelReese Hospital and Medical Center for referral of patient 2, Rosemary Lemons for performing the leukocyte cystine assays, and Tim Graves for preparing the figures.

This work was supported by grant 1 R01 FD 01263-01 from the Food and Drug Administration and grants 5 M01 RR42 and AM 25548 from the National Institutes of Health.

\section{References}

1. Abiko, Y. 1975. Metabolism of coenzyme A. In Metabolism of Sulfur Compounds. D. M. Greenberg, editor. Academic Press, Inc., New York. 1-25.

2. Maggi, G., C. Donate, and G. Criscuoli. 1982. Pantethine, a physiological lipomodulating agent, in the treatment of hyperlipidemias. Curr. Ther. Res. 32:380-386.

3. Avogaro, P., G. Bon, and M. Fusello. 1983. Effect of pantethine on lipids, lipoproteins and apolipoproteins in man. Curr. Ther. Res. 33: 488-493.

4. Galeone, F., A. Scalabrino, F. Giuntoli, A. Birindelli, G. Panigada A. Rossi, and P. Saba. 1983. The lipid-lowering effect of pantethine in hyperlipidemic patients: a clinical investigation. Curr. Ther. Res. 34: 383-390.

5. Maioli, M., A. Pacifico, and G. Cherchi. 1984. Effect of pantethine on the subfractions of HDL in dislipidimic patients. Curr. Ther. Res. 35:307-311.

6. Prisco, D., P. Rogase, M. Matucci, G. Costanzo, and G. Gensini. 1984. Effect of pantethine treatment on platelet aggregation and thromboxane $\mathrm{A}_{2}$ production. Curr. Ther. Res. 35:700-706.

7. Angelico, M., G. Pinto, C. Ciaccheri, D. Alvaro, A. DeSantis, M. Marin, and A. Attili. 1983. Improvement in serum lipid profile in hyperlipoproteinaemic patients after treatment with pantethine: a crossover, double-blind trial versus placebo. Curr. Ther. Res. 33:1091-1097.

8. Gaddi, A., G. Descovich, G. Nosed, C. Fragiacomo, L. Colombo, A. Craveri, G. Montanari, and C. Sirtori. 1984. Controlled evaluation of pantethine, a natural hypolipidemic compound, in patients with different forms of hyperlipoproteinemia. Atherosclerosis. 50:73-83.

9. DaCol, P., L. Cattin, M. Fonda, M. Mameli, and F. Feruglio.
1984. Pantethine in the treatment of hypercholesterolemia: a randomized double-blind trial versus tiadenol. Curr. Ther. Res. 36:314-322.

10. Ranieri, G., R. Chearappa, M. Balestrazzi, G. Gattulli, and R. De Cesaris. 1984. Effect of pantethine on lipids and lipoproteins in man. Acta Ther. 10:219-227.

11. Miccoli, R., P. Marchetti, T. Sampietro, L. Benzi, M. Tognarelli, and R. Navalesi. 1984. Effects of pantethine on lipids and apolipoproteins in hypercholesterolemic diabetic and nondiabetic patients. Curr. Ther. Res. 36:545-549.

12. Ono, S., K. Kameda, and Y. Abiko. 1974. Metabolism of pantethine in the rat. J. Nutr. Sci. Vitaminol. 20:203-213.

13. Butler, J. DeB., and M. Zatz. 1983. Pantethine depletes cystinotic fibroblasts of cystine. J. Pediatr. 102:796-798.

14. Butler, J. DeB., and M. Zatz. 1984. Pantethine and cystamine deplete cystine from cystinotic fibroblasts via efflux of cysteamine-cysteine mixed disulfide. J. Clin. Invest. 74:411-416.

15. Schneider, J. A., and J. D. Schulman. 1983. Cystinosis. In The Metabolic Basis of Inherited Disease. J. B. Stanbury, J. B. Wyngaarden, D. S. Fredrickson, J. L. Goldstein, and M. S. Brown, editors. McGrawHill Inc., New York. Fifth ed. 1844-1866.

16. Gahl, W. A., F. Tietze, N. Bashan, R. Steinherz, and J. D. Schulman. 1982. Defective cystine exodus from isolated lysosome-rich fractions of cystinotic leukocytes. J. Biol. Chem. 257:9570-9575.

17. Jonas, A. J., M. L. Smith, and J. A. Schneider. 1982. ATP-dependent lysosomal cystine effux is defective in cystinosis. J. Biol. Chem. 257:13185-13188.

18. Thoene, J. G., R. G. Oshima, J. C. Crawhall, D. L. Olson, and J. A. Schneider. 1976. Intracellular cystine depletion by aminothiols in vitro and in vivo. J. Clin. Invest. 58:180-189.

19. Yudkoff, M., J. W. Foreman, and S. Segal. 1981. Effects of cysteamine therapy in nephropathic cystinosis. N. Engl. J. Med. 304:141145.

20. Schneider, J. A., J. D. Schulman, and J. G. Thoene. 1981. Cysteamine therapy in cystinosis. $N$. Engl. J. Med. 304:1172.

21. Wittwer, C. T., D. Burkhard, K. Ririe, R. Rasmussen, J. Brown, B. W. Wyse, and R. G. Hansen. 1983. Purification and properties of a pantetheine-hydrolyzing enzyme from pig kidney. J. Biol. Chem. 258: 9733-9738.

22. Dupre, S., and D. Cavalinni. 1979. Purification and properties of pantetheinase from horse kidney. Methods Enzymol. 62:262-267.

23. Orloff, S., J. DeB. Butler, D. Towne, A. B. Mukherjee, and J. D. Schulman. 1981. Pantetheinase activity and cysteamine content in cystinotic and normal fibroblasts and leukocytes. Pediatr. Res. 15:10631067.

24. Pellett, O. L., M. L. Smith, J. G. Thoene, J. A. Schneider, and A. J. Jonas. 1984. Renal cell culture using autopsy material from children with cystinosis. In Vitro (Rockville). 20:53-58.

25. Knott, R. P., D. P. N. Tsao, R. S. McCutcheon, V. H. Cheldelin, and T. E. King. 1957. Toxicity of pantetheine. Proc. Soc. Exp. Biol. Med. 95:340-341.

26. Schwartz, E., and R. E. Bagdon. 1964. Toxicity studies of some derivatives of pantothenic acid. Toxicol. Appl. Pharmacol. 6:280-283.

27. Corden, B. J., J. D. Schulman, J. A. Schneider, and J. G. Thoene. 1981. Adverse reaction to oral cysteamine use in nephropathic cystinosis. Dev. Pharmacol. Ther. 3:25-30.

28. Tachizawa, H. 1980. Metabolism of pantethine. Med. Pharmacol. Exp. 14:26-31.

29. Yoshimura, H., H. Shiraki, K. Oguri, and H. Tsukamoto. 1970 Metabolism of drugs. LXVI. Studies on the metabolic fate of pantethine. Yadugaku Zasshi. 90:364-369.

30. Nakamura, H., and Z. Tamura. 1972. Studies on the metabolites in urine and feces of rat after oral administration of radioactive pantethine. Chem. Pharm. Bull. 20:2008-2016.

31. Rozanov, A. Y., A. V. Lysenkova, V. I. Gunar, V. M. Kopelevich and L. N. Stepanova. 1980. Synthesis and study of pharmacokinetics of labeled pantethine and its sulfamide analog. Khim.-Farm. Zh. 14:6671.

32. Shibata, K., C. J. Gross, and L. M. Henderson. 1983. Hydrolysis 
and absorption of pantothenate and its coenzymes in the rat small intestine. J. Nutr. 133:2207-2215.

33. Shegeta, Y., and M. Shichiri. 1966. Urinary excretion of pantothenic acid and pantethine in human subjects. J. Vitaminol. (Kyoto). 12:186-191.

34. Avner, E. D., D. Ellis, and R. Jaffe. 1983. Veno-occlusive disease of the liver associated with cysteamine treatment of nephropathic cystinosis. J. Pediatr. 102:793-796.

35. Gahl, W. L., J. D. Schulman, J. G. Thoene, and J. Schneider. 1983. Hepatotoxicity of cysteamine? J. Pediatr. 103:1008-1009.

36. Wyse, B. W., C. Wittwer, and R. G. Hansen. 1979. Radioimmunoassay for pantothenic acid in blood and other tissues. Clin. Chem. 25:108-111.

37. Somogyi, M. 1945. Determination of blood sugar. J. Biol. Chem. 160:69-73.

38. Jonas, A. J., and J. A. Schneider. 1981. A simple, rapid assay for cysteamine and other thiols. Anal. Biochem. 114:429-432.

39. Lundquist, P., J. Martensson, B. Sorbo, and S. Ohman. 1980. Turbidimetry of inorganic sulfate, ester sulfate, and total sulfur in urine. Clin. Chem. 26:1178-1181.

40. Skoog, W. A., and W. S. Beck. 1956. Studies on the fibrinogen, dextran and phytohemagglutinin methods of isolating leukocytes. Blood. 11:436-454.

41. Oshima, R. G., R. C. Willis, C. E. Furlong, and J. A. Schneider. 1974. Binding assays for amino acids. The utilization of a cystine binding protein from Escherichia coli for the determination of acid-soluble cystine in small physiological samples. J. Biol. Chem. 249:6033-6039.

42. Lowry, O. H., N. J. Rosebrough, A. L. Farr, and R. J. Randall. 1951. Protein measurement with the Folin phenol reagent. J. Biol. Chem. 193:265-275.

43. Wittwer, C., B. Wyse, and R. G. Hansen. 1982. Assay of the enzymatic hydrolysis of pantetheine. Anal. Biochem. 122:213-222.

44. Harvey, S. C. 1980. Basic pharmacokinetics. In Remington's Pharmaceutical Sciences. A. Osol, G. Chase, A. Gennaro, M. Gibson, C. Granberg, S. Harvey, R. King, A. Martin, E. Swinyard, and G. Zink, editors. Mack Publishing, Easton, PA. 683-701.
45. Jonas, A. J., and J. A. Schneider. 1982. Plasma cysteamine concentrations in children treated for cystinosis. J. Pediatr. 100:321-323.

46. Branca, D., G. Scutari, and N. Siliprandi. 1984. Pantethine and pantothenate effect on the CoA content of rat liver. Int. J. Vitam. Nutr. Res. 54:211-216.

47. Millard, W. J., S. M. Sagar, D. M. D. Landis, and J. B. Martin. 1982. Cysteamine: a potent and specific depletor of pituitary prolactin. Science (Wash. DC). 217:452-454.

48. Palkovits, M., M. J. Brownstein, L. E. Eiden, M. C. Beinfeld, J. Russell, A. Arimura, and S. Szabo. 1982. Selective depletion of somatostatin in rat brain by cysteamine. Brain Res. 240:178-180.

49. Guehring, R. R., L. S. Hurley, and A. F. Morgan. 1952. Cholesterol metabolism in pantothenic acid deficiency. J. Biol. Chem. 197: 485-493.

50. Scudi, J. V., and M. Hamlin. 1942. The effect of pantothenic acid deficiency on the blood lipoids of the dog. J. Nutr. 24:273-282.

51. Hodges, R. E., M. A. Ohlson, and W. B. Bean. 1958. Pantothenic acid deficiency in man. J. Clin. Invest. 37:1642-1657.

52. Wirtschafter, Z. T., and J. R. Walsh. 1962. Hepatocellular lipid changes produced by pantothenic acid excess. Ann. Surg. 156:97-104.

53. Durr, I. F., and N. Cortas. 1964. The reduction of pantethine by an extract of camel intestine. Biochem. J. 91:460-463.

54. Pearson, P. B. 1941. Studies on the metabolism of pantothenic acid in man and rabbits. Am. J. Physiol. 135:69-76.

55. Fox, H. M., and H. Linkswiler. 1961. Pantothenic acid excretion on three levels of intake. J. Nutr. 75:451-454.

56. Reibel, D. K., B. W. Wyse, D. A. Berkich, and J. R. Neely. 1982. Coenzyme A metabolism in pantothenic acid-deficient rats. J. Nutr. 112: $1144-1150$.

57. Karnitz, L. M., C. J. Gross, and L. M. Henderson. 1984. Transport and metabolism of pantothenic acid by rat kidney. Biochim. Biophys. Acta. 769:486-492.

58. Melander, A. 1978. Influence of food on the bioavailability of drugs. Clin. Pharm. 3:337-351.

59. Thoene, J. G., and R. Lemons. 1980. Cystine depletion of cystinotic tissues by phosphocysteamine (WR638). J. Pediatr. 96:1043-1044. 